\title{
Exploring Adaptive Teaching Competencies in Big Data Era
}

\author{
https://doi.org/10.3991/ijet.v12i03.6434 \\ Miftachul Huda \\ Universiti Teknologi Malaysia, Sekudai, Johor, Malaysia \\ halimelhuda@gmail.com \\ Andino Maseleno \\ Universiti Brunei Darussalam, Brunei Darussalam \\ andimaseleno@gmail.com \\ Masitah Shahrill \\ Universiti Brunei Darussalam, Brunei Darussalam \\ masitah.shahrilleubd.edu.bn \\ Kamarul Azmi Jasmi \\ Universiti Teknologi Malaysia, Sekudai, Johor, Malaysia \\ qamar@utm.my \\ Ismail Mustari \\ Universiti Teknologi Malaysia, Sekudai, Johor, Malaysia \\ mohdismail@utm.my \\ Bushrah Basiron \\ Universiti Teknologi Malaysia, Sekudai, Johor, Malaysia \\ bushrah@utm.my
}

\begin{abstract}
-in the last decade, the adoption of digital tool to support educational process has been emerged among the universities around the world. In big data era, the demand to utilize it in adaptive teaching should be considered to enable the teaching performance especially in accessing the resources. This paper aims to explore the framework model as a way for teachers in adapting big data to help their teaching performance especially in accessing the resources. The literature review was conducted from peer review journals, books and conferences. The findings reveal that process and management skills should be engaged into adaptive teachings competencies. It included commitment in planning, time management, and technology skills. This study is expected to contribute in strengthening teaching performances in the application guideline in the big data era to support assessing the multi-channels of sources of knowledge to extract new insights of value in exploring the adaptive teaching competencies.
\end{abstract}

Keywords-Adaptive teaching competency, big data, Process and management skills 


\section{Introduction}

In the digital era, taking benefit from Information and Communication Technology (ICT) with its recent development has been emerged widely amongst society's daily life for instance virtual interaction [1], virtual counselling [2,3,4], business [5,6], online tourism service $[7,8]$ and public service online system $[9,10]$. It can be viewed that this rapid growth has been a keystone in underlying such activities to enhance the easiness and convenience. In education, especially higher education, most of them adopted it to support the learning and teaching process. Regarding integral part of teaching and learning activities by the use of technologies, the current educational development ensures the student-centered teaching practices to enable them to get improve in supporting active students' learning [11]. Moreover, integrating technology in education can facilitate the performance of learning and teaching through improving the technological application with its management and skills [12]. It is not only the process, but also resources which should be accessed easily. For instance, smartphone usage in learning with its potential integration refers to how to support the systematic change to enable in facilitating the resources easily by online [13,14]. As a result, the one which should be potentially paid serious attention in creating, using, and managing appropriate technological processes and resources in online learning is teacher professional skills and development, where this refers to the adaptive teaching competency [15]. It plays a key role to direct properly in the process in giving instruction to drive how the process of the students' learning performances can be enhanced as supposed. To help bringing a systematic change with amounts of resources to support the adaptive teaching, the way of engaging the pedagogical skills and technological adoption can be integrated to give an impact of professional development on teachers' abilities to uptake and integrate the use of technology in their teaching [16]. Moreover, the way to absorb information and sources using online, one of which is big data, one of the new versions of technologies with such architectures among its generation, should be prepared well in the adaptive teaching competency.

Big data, which is one of the latest internet version platforms, becomes widely known to support in collecting, aggregating and analyzing very large amounts of data $[17,18]$. In addition, online resource has been challenging task to provide an appropriate way since sometimes such massive data provided is not adjusted yet with a balance towards the teacher's professional skills and developments [19,20,21]. With regard to the way to accessing information and online sources available by online amongst the students, teacher or instructor can give the keyword about the certain topic, so students may search for themselves such information needed. As a result, the approach to integrate the big data techniques into the adaptive style of teaching would give a significant essence to give such benefits. To achieve this, it is necessary to provide the application guideline amongst the teachers to strengthen their adaptive teaching competencies in big data era. As a result, this paper aims to propose the framework model of adaptive teaching competency in the big data era to support assessing the multi-channels of sources of knowledge to extract new insights of value in supporting the adaptive teaching competencies. 


\section{$2 \quad$ Literature Review}

\subsection{Towards Adaptive Teaching Competencies}

Between theory and practice, innovative teaching has to do with the competency basis which refers to professional skill with ethical balance which covers cognitive, affective and emotional scale [22,23]. Related to the competency which teachers should behave, four main competencies obtained to enhance the teaching performance are learning competence, social competency, educational competency, and technological competency [24].

\section{Elements of teaching competencies}
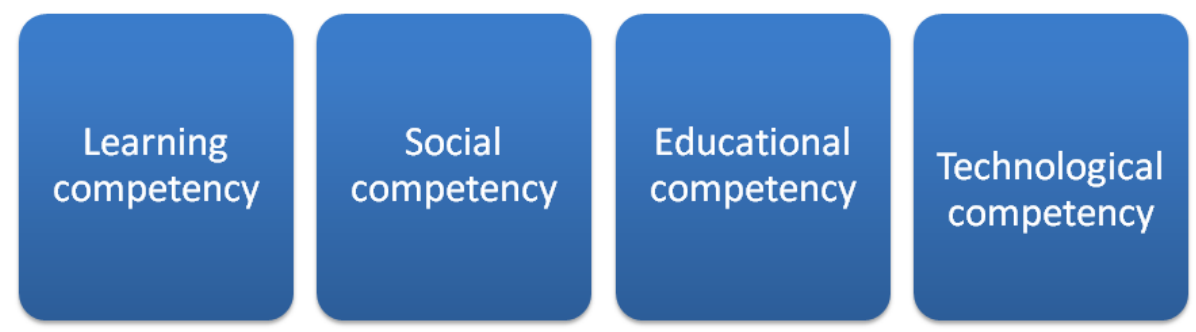

Fig. 1. Elements of teaching competencies [24]

Showing four elements of teaching competencies as mentioned above, all these refer to play a key role in supporting the teaching process with pedagogical, ethical and professional basis. The way which teachers usually exert in their performance is entirely a variety of the ways on teaching skills integrated with technological adoption $[25,26]$. Widely known as adaptive teaching, this concept has been considered as an ability to adapt teaching competency in such way to enable in performing subject knowledge [27]. As a result, the situational aspect with the conditions on learning processes relates to the topical themes which refer to the dimension of teaching style. The teaching methods which have a variety of fruitful conditions into the students' learning should be supported with engaging the dimension of classroom management. In this view, the regulation about learning processes with its activities managed in the class requires the teachers with their adaptive teaching competency to have selfregulated management oriented to the teaching on certain subject knowledge. In addition, the adaptive teaching style would be covered into scaffolding students' learning in adapting their instruction to working the particular situations. Such pattern is linked 
to the students' learning outcome which refers to understanding, doing and demonstrating what they learn. The way to concisely manage the classroom has to do with teacher's content knowledge in terms of the subject matter and interpersonal behavior on how to interact with students. Moreover, it includes teacher motivation with interpersonal behavior and classroom management.

\subsection{About Insights of Big Data in Education}

Widely recognized as the platform to the extent in accessing, storing and transmitting information from the convergence of data created on every second across the internet by enabling high-velocity capture, big data is designed to utilize the massive amounts of data subsequently extracted to gain its potential and value for the user $[28,29]$. With the advanced number of data deriving from the variety of information including velocity and volume, to obtain the valuable essences to transform big data practices to gain its value is necessary to adjust in advancing the insights of processing customization, personalization and intervention to create the particular value to enable in the further process [30,31]. In gaining an insight from multiple sources as a key role to maintain the competitive advantage like multiple business scenarios, through the link system coordinated to such large device, the ability to explore data gathered can be applied in helping many sectors in offering personalized and customized service $[32,33]$. With regard to the amount of data generated through such device using internet to enable the society in transferring data information to run in predicting the user needs, transferring data information will ensure the ability to discover insights of data from the variety of context which covers the services processes. Exploring data used in the real time to offer personalized and customized services enables in providing great chances to maximize the data potential with big data practices. By providing new opportunities to maximize the potential of data collection in online learning systems [34] and also innovative teaching [35], the concept of big data with these opportunities can give benefit by offering such customization and personalization of knowledge and services with more precise.

\section{Method}

This study aims to examine the adaptive teaching competencies in big data era. To see the adaptive teaching adjusted to the current trend in big data era, model design engaged with examining literature was employed. The researchers employ metasynthesis to propose model of future recommendations of adaptive competencies of teaching. Empirical basis of literature was selected in the basis of big data and teaching competencies from peer reviewed journals, books and conferences.

Exploring the distinct model on teaching competencies, several stages were conducted using meta-synthesis covering searching for bibliographic information, organizing substantive keywords, analyzing and interpreting such empirical work. This is how the research framework was conducted. With approaching such research frame- 


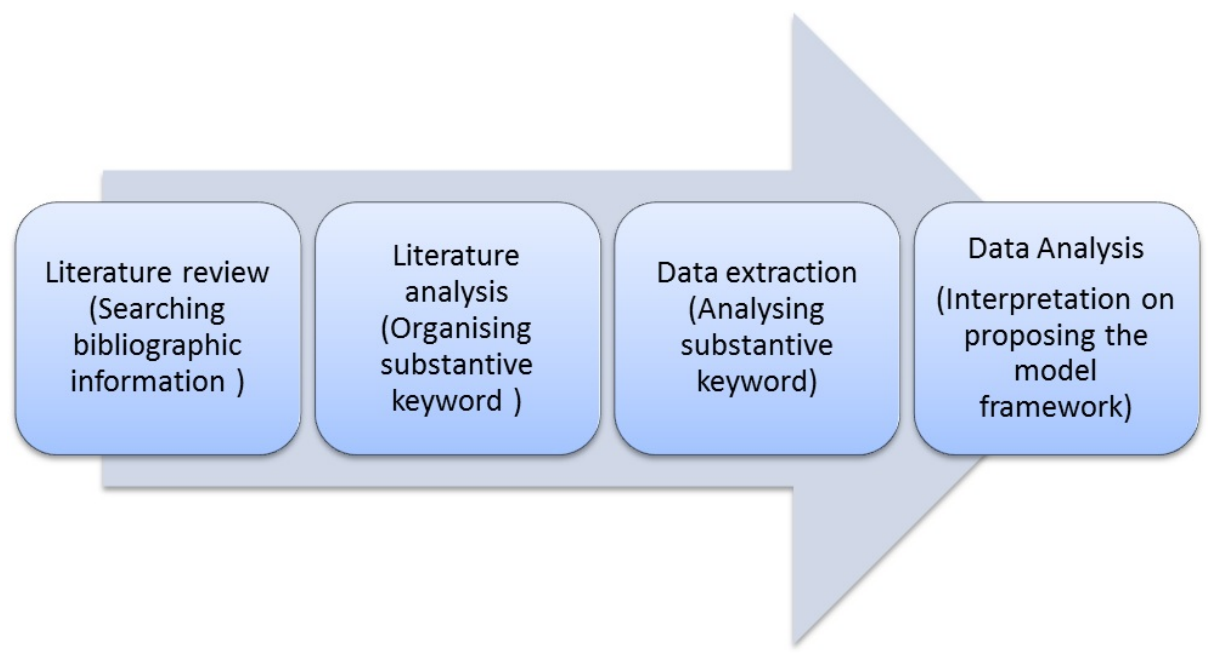

Fig. 2. Research framework

work, attempts to search for topic information from empirical basis was carried out. This is to help finding the research problem and gap to contribute. Subsequently, existing work was perused with deeply analyzing to investigate the particular content based on the substantive word. Furthermore, organizing and extracting the substantive word were employed to synthesize the interpretation of findings. Further analysis at this stage to propose framework model was carried out using met-synthesis to propose the framework model on adaptive competencies in big data era.

\section{$4 \quad$ Analysis And Discussion}

\subsection{Big Data Analytic Process}

With the particular feature to run the process of examining large data set out from structured data and unstructured one, big data analytic has been the pattern to cover in assessing data from the hidden patterns, correlations and other insights in analyzing the data and getting answers from it almost immediately [36]. As the new generation of data analysis approach covers the stage from collecting and aggregating the large amount of data, and then analysis in depth approach was conducted [37], big data utilizes such massive amounts of data created in every second across the Internet and then it is extracted to gain its potential and value for the user [38]. For instance, an online learning from the materials provided by the instructor can be supplied with relevant and reliable links to resources, within three main headings: directed, automated, and volunteered [30]. With big data adoption, generating records of the users' lives can be made by frequently posting details of activities to develop the course structure or make decisions based on this context [39]. By various students' blogs to understand their learning quality for instance, the instructor can provide such content 
appropriate with personal learning needs. In further, transferring such data from their activities can be generated in the approach of pattern coming from volunteering data, mainly from third parties [40]. Whenever they search for information that is needed, the students are provided with the answers and feedback through further links to material related to the concepts covered by the questions [41]. It indicates that based on big data analytics, it is possible to forecast which teaching instructor can pass the subject or course by providing it with an accurate way of understanding surveillance data gathering in this context.

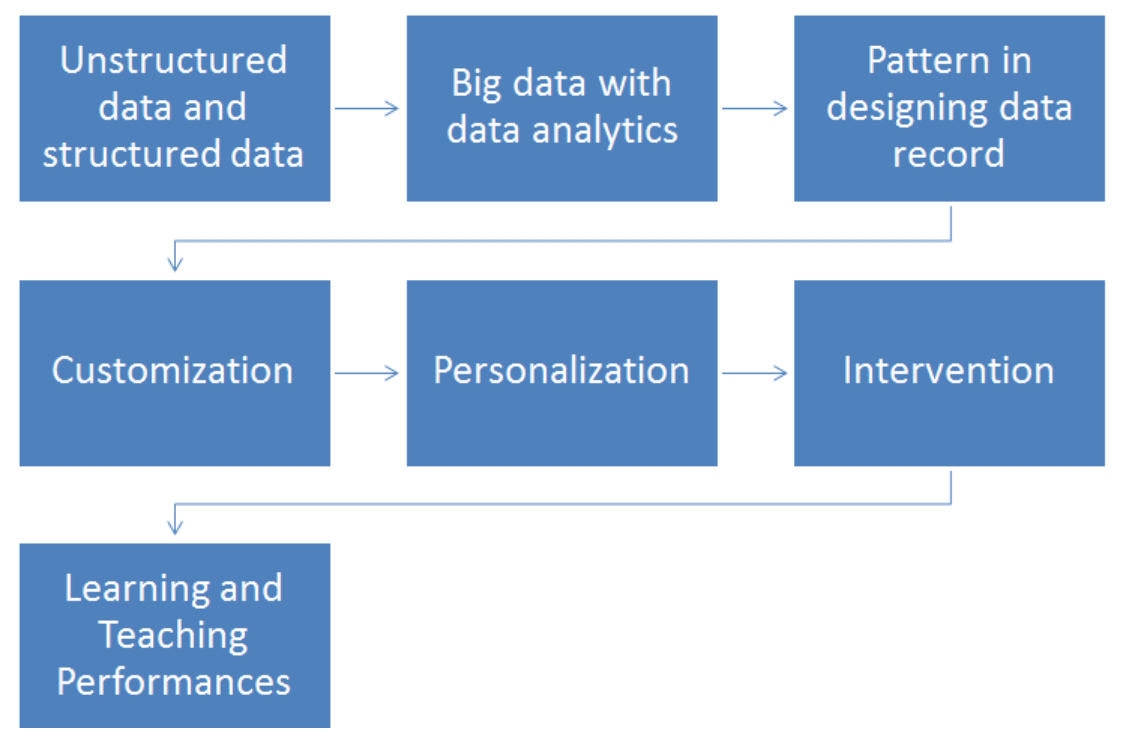

Fig. 3. Big data analytic process

As illustrated on the figure above, big data analytic is the process with broadest platform for examining large data by capturing, managing and proceeding data. Through these three core processes, data analysis with extracting pattern from customer preferences can be generated through data analytic process to identify information on market trends. In this regard, data extraction comes from structured data and unstructured one [36]. Structured data here come from the user' record which included searching for information using web basis, internet browsing and also elibrary record. In short, this can be seen through such sources from user or customer. Moreover, the process to extract massive amounts of data can also come from audio's preferred records, CCTV to record any kind of events happening. Referring to such sources, actualizing the prediction on the pattern is known as unstructured data. Getting service in advance can be resulted from personalizing and customizing the pattern and prediction generated through data analytic. Data analytic is systematically generated into the prediction and pattern to deliver the customization and personalization. Here comes to pursue the teaching and learning process where data analytic process is aligned with customization to ensure the record, which is the pattern resulted from user's preferences data. 


\subsection{Exploring Adaptive Teaching Competencies in Big Data Era}

About the adaptive teaching competencies referring to the approaches which can be implemented including teaching strategies and techniques, these skills can facilitate teachers to improve their performance through using digital tool [19]. In line with such approaches which teachers may use to generate their teaching performance, big data analytics process can provide the platform which teachers may utilize in preparing the online sources in the way which students may also access to support their learning [32,33]. As a result in generating the basic condition for technologyenhanced learning environment, its integration with critical components typically through the approach including skills, knowledge and critical thinking can accomplish the students' background knowledge, environment, and their learning instruction covered within the standardized curricula [19]. Committed to incorporating big data evidentially tempered by a cautious and critical approach and by the influence of external constraints, teachers may have a great chance to effectively implement teaching competencies adapted to enable in empowering instructors [35]. It would ensure to fulfill their plans adjusted to the students' needs. Moreover, by deeply understanding the way to access sources, emerging forms of activity amongst the students can be accomplished into the learning goal. Selecting the way on how to gain resources using big data approach to supplement the information needed effectively in the way that can be achieved easily should be combined with the technological skills among the teacher. It refers to enhance knowledge acquisition amongst the student in searching for such information which benefit for them in supporting their learning. As a result, innovative teaching using big data approach has such core stages of competencies which underlie the process in a whole context. It includes teaching and learning, social and technology competency as indicated in Figure 4.

Figure 4 indicates big data analytics process to generate and support innovative teaching which can be considered in offering adaptive competences in teaching per-

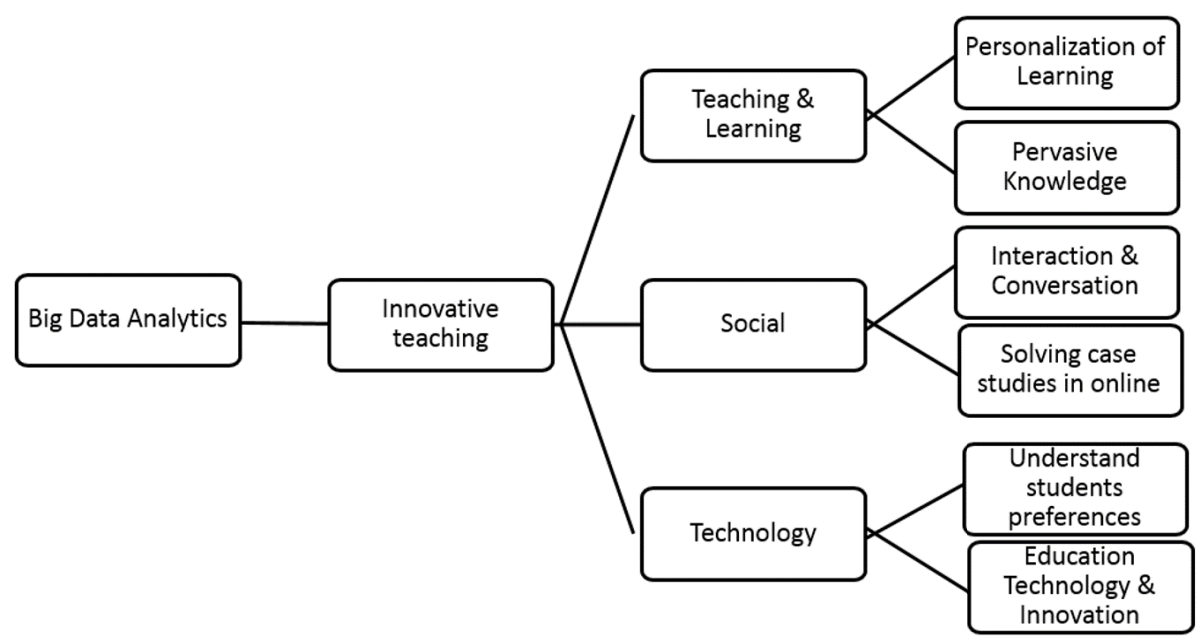

Fig. 4. Big data in innovative teaching process [35] 
formances mainly in higher education setting. Among the teaching and learning competencies, teachers can benefit such resources to help providing information sources. With this regard, LMS (Learning Management System), mobile learning and also social network site (SNS) all these refer to how to raise online learning and teaching performances [42]. Moreover, social aspect and technology skill have been mainly concerned to underlie the process with maximizing prediction and customization regarded into the pattern $[43,44]$. The ability with skills to use technology in the way to providing a considerable guidance for child protection and careful engagement towards digital information should be taken into consideration towards taking care into the adaptive technology skills [59]. This aims to strengthen the way to natural growth and development. In addition to the technology skills, the ability to generate process using digital devices like mobile or laptop refers to the way and knowledge in adopting and using effectively and efficiently.

Since the effectivities on teaching performance is dependent on how to implement the good way in using the strategy, the mastery on teaching method has the consequence to drive the characteristics on the variety of teacher factors related to the student learning outcome [26]. With this regard, the proposed model here is initiated to the way on management and skills process involving: optimizing time management, strengthening commitment in planning and developing technology skills as a result of suggestion on obtaining the teaching performances in digital era.

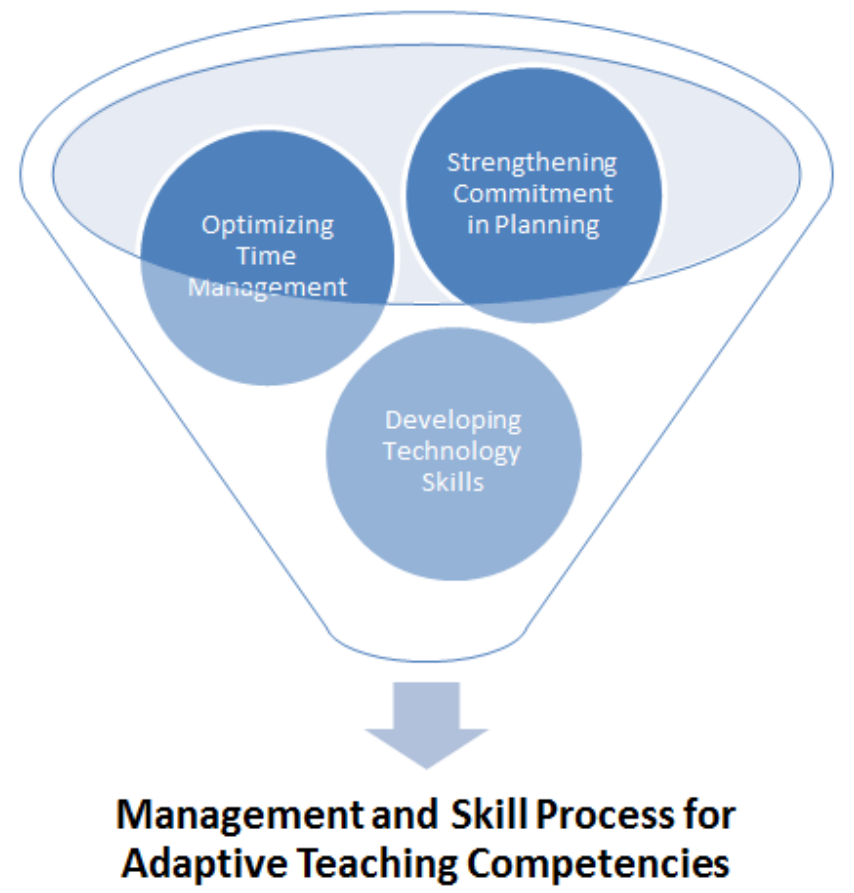

Fig. 5. Management and skill process for adaptive teaching competencies 
Figure 5 illustrated the management and skills process for adaptive teaching competencies should be transmitted into the pedagogical knowledge which teachers should engage with in the classroom setting basis. As a result, adaptive teaching competencies become the pattern with its concepts of dimensions which enable the teachers to achieve the competencies including subject matter of certain field of knowledge [45]. In this regard, the students' outcome is the main concern among the teachers to strengthen teaching strategy and also management approach in classroom. Big data techniques can be utilized in providing the lens for teacher in adaptations to manage the way of teaching $[46,47]$. It indicates that integrating the adaptive way with typically emphasizing critical thinking and regulating one's thinking could be engaged in monitoring and regulating the instruction. In terms of strategic instruction, big data analytic process can give the cognitive articulation with instructional response to help teachers in regulating the resources based on the pattern recorded in data [48]. Resulted from the imperative approach in teaching and learning, big data can be generated through such digital devices for instance mobile learning, web based learning, social network site basis of learning, digital online learning application etc. It becomes the

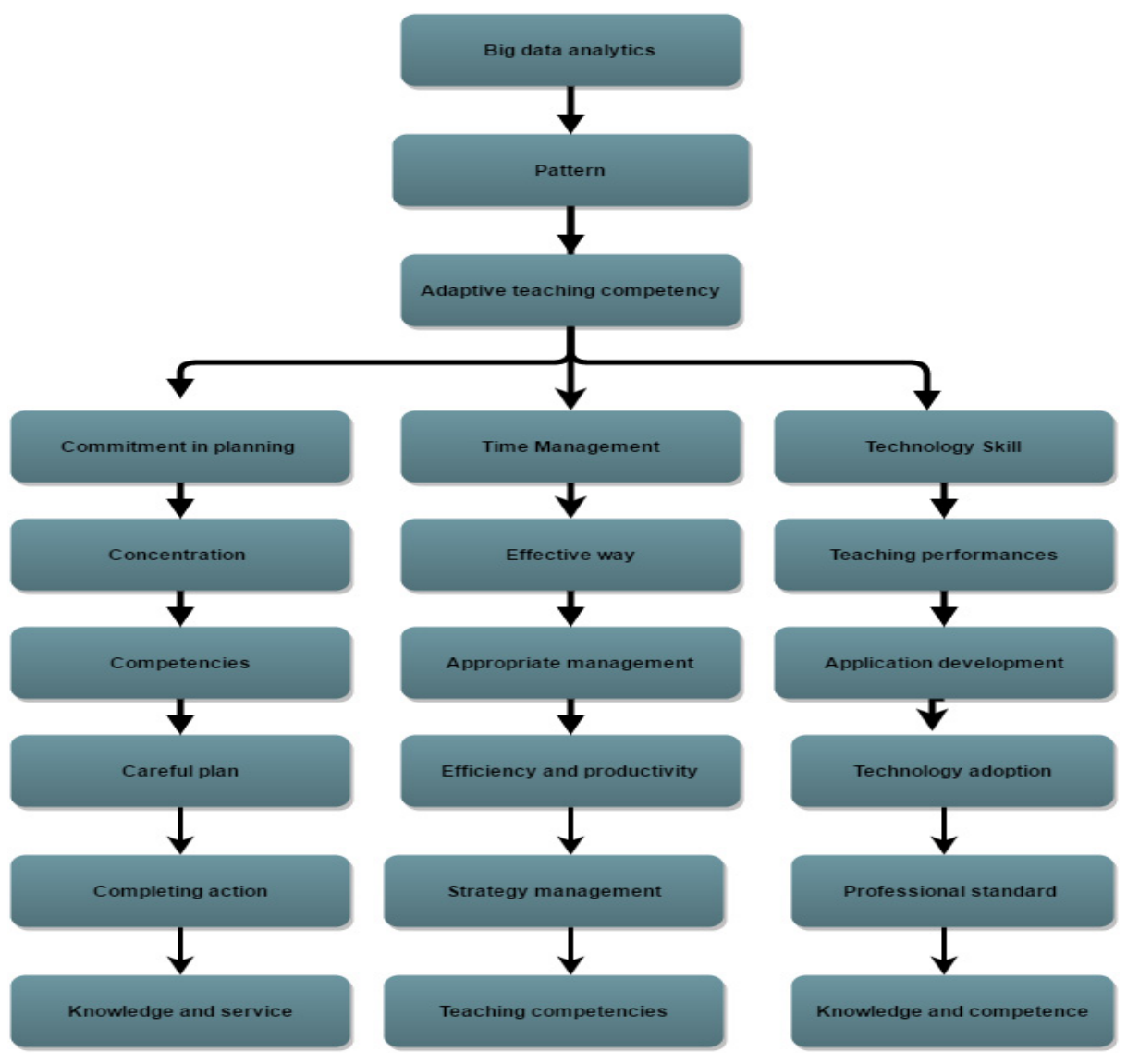

Fig. 6. Exploring adaptive teaching competencies in big data era 
significant role to all teachers to support teachers' pedagogical skills together with assessing multiple sources as the large portion with specific way of adaptive teaching in imaginative instruction. As a result, the adaptive way on the teaching performance has to do with innovative teaching where the prominence on teachers' cognition could be gained particularly into attracted significant interest. In maintaining the competitive advantage to give a feedback into adaptive teaching performance, the modeling of adaptive teaching competencies needs to construct the adoption in discovering the basic mechanisms that give insights into the teachers' technology use in exploring the resources with borderless.

Strengthening Commitment in Planning: With the key components to achieve spirit way in teaching competencies, commitment in planning becomes an essential habit which should belong to each instructor or teacher instructed to concentrate in finishing task in effective way [49]. Big data with its data analytics process needs to prepare a plan to run teaching process with strengthening competencies. As a result, the competencies here should be assigned to gather the skills on planning with development process to behave the manner in strengthening commitment with effective strategy. In order to obtain its significance with a variety of purposes, the way to strengthen commitment in planning to provide the way in building the commitment refers to being careful to the plans in building trust and commitment to complete actions [50]. Apart from that, to gather data accumulated into the pattern from customization, strategic planning becomes significant to drive in the process of analyzing massive data to see the user preferences $[51,52]$. To maximize the potential of data in attempting to enhance the teaching process in online learning systems for instance, commitment in providing new approaches with big data in innovative teaching offers customization and personalization to optimize such opportunities between knowledge and service [53]. With the concept of big data, both students and service providers can enhance customization from multi channels of resources. Emphasizing the use of big data needs to consider in both complemented and modified practice. Transforming such sufficient support to teaching performance between academic skills and social interaction for instance, big data can be set out checking on the voluntary data to influence the effectiveness of learning with technological tool [32,33]. As a result, through accessing massive data gathered from such platforms like administrative records or customer pattern, collecting data through continuous sensing with the link of all sorts of unstructured data structured in real time from human digital activity plays a key role in monitoring the pattern resulted from the use of assessments which created numerical data. As outstanding effort to enhance providing teaching approach with such indicators in online resources, the combination of big data and predictive analytics in the digital technologies is being committed to the particular skills and interest designed with common core elements and themes in teaching competencies.

Optimizing Time Management: Time management is important at any field of work including business, education and government sector. It has a significant role to run the process of organizing and planning to utilize wisely in a way to make specific activities run in effective way. In line with digital era, it has a challenge and chance to deliver the process flowy. Towards the large amount of data recorded in education for instance, big data offers benefit which can be converted to analyse the pattern from 
user preferences data [48]. In addition to the teaching, the ability to manage time appropriately and effectively on such data to see how the students' main concern is entirely supposed to personalise their preferences generated into the pattern refers to increase the process with more effectiveness [49]. With this regard, big data application requires an important transformation to focus on particular and necessary activities with time management to gain efficiency and productivity adjusted to the plan. The effectiveness in managing time to access online sources of necessary and useful matter seems dependent with particular manner on time management [54]. Dedicated to utilise material sources, big data in generating the potential components of pattern makes an effective way in the strategy to prepare the appropriate content relevant to the students. The way and manner by which to organize as planned have to do usually with managing knowledge on big data application as in the analytic process to arrange such skills to enhance the improvement which students and teachers may simultaneously gain. With such improvement, gathering the essence on time management techniques is to develop effective strategies in big data approach to lead in achieving the attainment of teaching performance to behave competencies.

Developing Technology Skills: As the essential part to enhance the teaching performance, technology skill is eventually used to support teaching and learning. It is considered as an important part to run the process with more convenience. In the use of such devices like laptop, tablet or smartphone, all these refer to help the process well with application development by which student can benefit [43]. Big data with its features of analytics process is designed to generate data from the user's preference in the 'pattern' so that teacher or instructor can prepare some resources in online learning platform like canvas or other similar [41]. Later, students can get access to see their assignment and sources uploaded in online platform. To achieve this well in the way that can develop teaching performance, technology skills should be paid serious attention to run the process in appropriate way. Moreover, skills of data analysis should be specifically adjusted to a piece of equipment which can make such distinctive feature in technology use and adoption [54]. With this regard, big data analytic process using personalization comes from the data recorded in the platform so it can be easily predicted to give sources in online learning. As a result, several stages which need to concern deeply include security, progress development, and analysis skills of operating data. In particular, performing the professional standard in such activities to promote the improvement of knowledge, skills and competence becomes one of the main ultimate factors which affect the teaching process.

\subsection{Implications and Future Directions}

Since teaching material sources in online learning can be made from assessing data in every stage, formulating the competencies on the adaptive teaching is needed in assessing big data application. Moreover, learning with comprehensive approach [55] may also be supported in order to deliver adaptive teaching [56]. Numerous sources give complex of data like social networks, surveys, newspapers, magazines generated to the speed, volume and assortment. Apart from that, the importance of being committed for the teacher to maximize the big data approach [35] is significantly a core 
requirement to ensure positive teaching and learning process necessarily anywhere and anytime [32]. The pedagogical aspect would give a significant contribution to support the teaching process by multitude resources. As a result, the teacher's role in encouraging students to explore online resources with paying attention into commitment in planning, time management and technology skills which are well prepared may become supportive instruction to enable them to get more benefits for their development, performance and achievement in teaching process. Considering competencies among the teacher in big data era, these benefits make a particular interest to encourage students to interact with instructional process in both class and outside, so they can get improve socializing and thinking skills to boost their confidence. Consequently, pedagogical skills teachers may need to enhance their skills in adopting big data approach become necessary part of applying such approach into the teacher's proper guidance to students. It is regarded as a significant role to control the way students go through online learning to avoid any problem such as misusing, abusing and bullying in order that they may get the learning access through strengthening their ability and learning preferences [57]. Providing greater access to current, high-quality information, which are distinct kinds: engagement, interaction and meaningful learning, can help motivate the students and improve their attentiveness in class [58].

In addition to determining the quality of teaching competencies adapted to big data analytics approach, building skills and knowledge to develop innovative teaching becomes a core element to play role to enhance progressive knowledge to ensure in supporting teaching and learning instruction. With this regard, teacher can upgrade more by improving the skills of big data based teacher education in the way that is effective and efficient. For instance, by preparing such basic skills in big data approach like preparing, introducing and managing learning arrangements from online sources both teacher and student are necessary to mastery those to be successfully implemented. In addition to the level of university, supporting the learning process where the supportive initiative can be prepared through using laptop in learning process with multi-place would be a better facilitation to support teachers and students' activities.

\section{Conclusion}

This paper did explore the way for teachers in adapting technological tool to help their teaching performance especially in accessing the resources of the teaching matters. The approach to integrate into the big data techniques into the adaptive style of teaching would give a significant essence as the framework model. By incorporating the adaptive style of teaching performance using big data framework setting, this paper aims to contribute the application guideline in the big data era to support assessing the multi-channels of sources of knowledge to extract new insights of value in exploring the adaptive teaching competencies. To achieve this, it is required to enhance the competency for the teacher to strengthen the framework model. In this view, the adaptive teaching competencies in big data era should be prepared to achieve adaptive style for supporting teaching. There are three core adaptive teach- 
ings which should be considered in the teacher performances, namely commitment in planning, time management, and technological tools utilization. This study is expected to contribute in strengthening teaching performances to adapt the technological tool.

\section{References}

[1] Livingstone, S. (2012). Critical reflections on the benefits of ICT in education. Oxford review of education, 38(1), 9-24. https://doi.org/10.1080/03054985.2011.577938

[2] Kimani, E., Bickmore, T., Trinh, H., Ring, L., Paasche-Orlow, M. K., \& Magnani, J. W. (2016, September). A Smartphone-Based Virtual Agent for Atrial Fibrillation Education and Counseling. In International Conference on Intelligent Virtual Agents (pp. 120-127). Springer International Publishing. https://doi.org/10.1007/978-3-319-47665-0 11

[3] Witt, K. J., Oliver, M., \& McNichols, C. (2016). Counseling via Avatar: Professional Practice in Virtual Worlds. International Journal for the Advancement of Counselling, 38(3), 218-236. https://doi.org/10.1007/s10447-016-9269-4

[4] Zakirillah, Noorminshah, A. I., Huda, M., Fathoni, \& and Heroza, R. I. (2016). Design of a Mobile based Academic Cyber Counselling Application in Higher Education. Journal of Information Systems Research and Innovation, 10(3), 1-9.

[5] Salleh, A., Hamzah, R., Nordin, N., Ghavifekr, S., \& Joorabchi, T. N. (2015). Online counseling using email: a qualitative study. Asia Pacific Education Review, 16(4), 549563. https://doi.org/10.1007/s12564-015-9393-6

[6] Casero-Ripollés, A., \& Izquierdo-Castillo, J. (2013). Between decline and a new online business model: The case of the Spanish newspaper industry. Journal of Media Business Studies, 10(1), 63-78. https://doi.org/10.1080/16522354.2013.11073560

[7] Basoglu, K. A., \& Hess, T. J. (2014). Online business reporting: A signaling theory perspective. Journal of Information systems, 28(2), 67-101. https://doi.org/10.2308/isys50780

[8] Law, R., Buhalis, D., \& Cobanoglu, C. (2014). Progress on information and communication technologies in hospitality and tourism. International Journal of Contemporary Hospitality Management, 26(5), 727-750. https://doi.org/10.1108/IJCHM-08-2013-0367

[9] Sotiriadis, M. D., \& Van Zyl, C. (2013). Electronic word-of-mouth and online reviews in tourism services: the use of twitter by tourists. Electronic Commerce Research, 13(1), 103124. https://doi.org/10.1007/s10660-013-9108-1

[10] Anshari, M., \& Almunawar, M. N. (2016). Mobile Health (mHealth) Services and Online Health Educators. Biomedical informatics insights, 8, 19.

[11] Anshari, M., \& Lim, S. A. (2016). Customer relationship management with big data enabled in banking sector. 3 (4),1-7.

[12] Smith, D., \& Hardaker, G. (2000). E-learning innovation through the implementation of an internet supported learning environment. Educational Technology \& Society, 3(3), 422432.

[13] Fenwick, T., \& Edwards, R. (2016). Exploring the impact of digital technologies on professional responsibilities and education. European Educational Research Journal, 15(1), 117-131. https://doi.org/10.1177/1474904115608387

[14] Anshari, M., Almunawar, M. N., Shahrill, M., Wicaksono, D. K., \& Huda, M. (2017). Smartphones usage in the classrooms: Learning aid or interference?. Education and Information Technologies, 1-17. https://doi.org/10.1007/s10639-017-9572-7 
[15] Dede, C., Ketelhut, D. J., Whitehouse, P., Breit, L., \& McCloskey, E. M. (2009). A research agenda for online teacher professional development. Journal of teacher education, 60(1), 8-19. https://doi.org/10.1177/0022487108327554

[16] Williams, D., Coles, L., Wilson, K., Richardson, A., \& Tuson, J. (2000). Teachers and ICT: Current use and future needs. British journal of educational technology, 31(4), 307320. https://doi.org/10.1111/1467-8535.00164

[17] Mayer-Schönberger, V., \& Cukier, K. (2013). Big data: A revolution that will transform how we live, work, and think. Houghton Mifflin Harcourt.

[18] Kitchin, R. (2014). Big Data, new epistemologies and paradigm shifts. Big Data \& Society, 1(1), 2053951714528481, 1-12. https://doi.org/10.1177/2053951714528481

[19] Ertmer, P. A. (2005). Teacher pedagogical beliefs: The final frontier in our quest for technology integration?. Educational technology research and development, 53(4), 25-39. https://doi.org/10.1007/BF02504683

[20] Vogt, F., \& Rogalla, M. (2009). Developing adaptive teaching competency through coaching. Teaching and Teacher Education, 25(8), 1051-1060. https://doi.org/10.1016/j.tate. 2009.04.002

[21] Opdenakker, M. C., \& Van Damme, J. (2006). Teacher characteristics and teaching styles as effectiveness enhancing factors of classroom practice. Teaching and teacher education, 22(1), 1-21. https://doi.org/10.1016/j.tate.2005.07.008

[22] Den Brok, P., Brekelmans, M., \& Wubbels, T. (2004). Interpersonal teacher behaviour and student outcomes. School effectiveness and school improvement, 15(3-4), 407-442. https://doi.org/10.1080/09243450512331383262

[23] Harris, J., Mishra, P., \& Koehler, M. (2009). Teachers' technological pedagogical content knowledge and learning activity types: Curriculum-based technology integration reframed. Journal of Research on Technology in Education,41(4), 393-416. https://doi.org/10.1080/15391523.2009.10782536

[24] Zhu, C., Wang, D., Cai, Y., \& Engels, N. (2013). What core competencies are related to teachers' innovative teaching?. Asia-Pacific Journal of Teacher Education, 41(1), 9-27. https://doi.org/10.1080/1359866X.2012.753984

[25] Salleh, S. (2016). Examining the influence of teachers' beliefs towards technology integration in classroom. The International Journal of Information and Learning Technology, 33(1), 17-35. https://doi.org/10.1108/IJILT-10-2015-0032

[26] Conklin, H. G. (2015). Preparing novice teacher educators in the pedagogy of teacher education. Action in teacher education, 37(4), 317-333. https://doi.org/10.1080/01626620. 2015.1078753

[27] Ertmer, P. A., \& Ottenbreit-Leftwich, A. T. (2010). Teacher technology change: How knowledge, confidence, beliefs, and culture intersect. Journal of research on Technology in Education, 42(3), 255-284. https://doi.org/10.1080/15391523.2010.10782551

[28] Villars, R. L., Olofson, C. W., \& Eastwood, M. (2011). Big data: What it is and why you should care. White Paper, IDC, 14.

[29] Chen, M., Mao, S., Zhang, Y., \& Leung, V. C. (2014). Big data: related technologies, challenges and future prospects (pp. 2-9). Heidelberg: Springer. https://doi.org/10.1007/ 978-3-319-06245-7

[30] Lyon, D. (2014). Surveillance, Snowden, and big data: Capacities, consequences, critique. Big Data \& Society, 1(2), 2053951714541861. https://doi.org/10.1177/205395171 4541861

[31] Cohen, J., Dolan, B., Dunlap, M., Hellerstein, J. M., \& Welton, C. (2009). MAD skills: new analysis practices for big data. Proceedings of the VLDB Endowment, 2(2), 14811492. https://doi.org/10.14778/1687553.1687576

[32] Anshari, M., Alas, Y., \& Guan, L. S. (2016). Developing online learning resources: Big data, social networks, and cloud computing to support pervasive knowledge. Education 
and Information Technologies, 21(6), 1663-1677. https://doi.org/10.1007/s10639-0159407-3

[33] Anshari, M., Alas, Y., Sabtu, N. I. P. H., \& Hamid, M. H. S. A. (2016). Online Learning: trends, issues and challenges in the Big Data Era. Journal of e-Learning and Knowledge Society, 12(1). 121-134.

[34] Daniel, B. (2015). Big data and analytics in higher education: Opportunities and challenges. British journal of educational technology, 46(5), 904-920. https://doi.org/10.1111/ bjet. 12230

[35] Huda, M., Anshari, M., Almunawar, M. N., Shahrill, M., Tan, A., Jaidin, J. H., \& Masri, M. (2016). Innovative Teaching in Higher Education: The Big Data Approach. The Turkish Online Journal of Educational Technology, 15(Special issue), 1210-1216.

[36] Hashem, I. A. T., Yaqoob, I., Anuar, N. B., Mokhtar, S., Gani, A., \& Khan, S. U. (2015). The rise of "big data" on cloud computing: Review and open research issues. Information Systems, 47, 98-115. https://doi.org/10.1016/j.is.2014.07.006

[37] Thompson, G. (2016). Computer adaptive testing, big data and algorithmic approaches to education. British Journal of Sociology of Education, 1-12. https://doi.org/10.1080/ 01425692.2016.1158640

[38] Abbasi, A., Sarker, S., \& Chiang, R. H. (2016). Big data research in information systems: Toward an inclusive research agenda. Journal of the Association for Information Systems, 17(2), 3 .

[39] Cope, B., \& Kalantzis, M. (2016). Big Data Comes to School: Implications for Learning, Assessment, and Research. AERA Open, 2(2), 2332858416641907. https://doi.org/10.1177/2332858416641907

[40] Wang, Y. (2016). Big opportunities and big concerns of big data in education. TechTrends, 60(4), 381-384. https://doi.org/10.1007/s11528-016-0072-1

[41] Anshari, M., Alas, Y., Hamid, M. H. S. A., \& Smith, M. (2016). Learning Management System 2.0: Higher Education. In Handbook of Research on Engaging Digital Natives in Higher Education Settings (pp. 265-279). IGI Global.

[42] Anshari, M., Alas, Y., \& Guan, L. S. (2015). Pervasive Knowledge, Social Networks, and Cloud Computing: E-Learning 2.0. Eurasia Journal of Mathematics, Science \& Technology Education, 11(5), 909-921.

[43] So, H. J., \& Kim, B. (2009). Learning about problem based learning: Student teachers integrating technology, pedagogy and content knowledge. Australasian Journal of educational technology, 25(1), 101-116. https://doi.org/10.14742/ajet.1183

[44] Vangrieken, K., Meredith, C., Packer, T., \& Kyndt, E. (2017). Teacher communities as a context for professional development: A systematic review. Teaching and Teacher Education, 61, 47-59. https://doi.org/10.1016/j.tate.2016.10.001

[45] Parr, J. M., \& Wilkinson, I. (2016). Widening the theoretical lens on talk and writing pedagogy. International Journal of Educational Research,80, 217-225. https://doi.org/10.1016/j.ijer.2016.08.011

[46] Bohlouli, M., Schulz, F., Angelis, L., Pahor, D., Brandic, I., Atlan, D., \& Tate, R. (2013). Towards an integrated platform for big data analysis. In Integration of practice-oriented knowledge technology: Trends and prospectives (pp. 47-56). Springer Berlin Heidelberg. https://doi.org/10.1007/978-3-642-34471-8 4

[47] Nagar, A. (2016, February). Enhancing Teaching of Big Data by Using Real World Datasets. In Proceedings of the 47th ACM Technical Symposium on Computing Science Education (pp. 496-496). ACM.

[48] Yang, J., \& Shen, J. (2016). Teaching Big Data by Three Levels of Projects. International Journal for Innovation Education and Research, 3(7).

[49] Adair, J. (2009). Effective time management: How to save time and spend it wisely. Pan Macmillan. 
[50] Hennessy, S., Ruthven, K., \& Brindley, S. (2005). Teacher perspectives on integrating ICT into subject teaching: commitment, constraints, caution, and change. Journal of curriculum studies, 37(2), 155-192. https://doi.org/10.1080/0022027032000276961

[51] Donovan, S. (2008). Big data: teaching must evolve to keep up with advances. Nature, 455(7212), 461-461. https://doi.org/10.1038/455461d

[52] Davis, K. (2012). Ethics of Big Data: Balancing risk and innovation. O'Reilly Media, Inc.

[53] Reyes, J. A. (2015). The skinny on big data in education: Learning analytics simplified. TechTrends, 59(2), 75-80. https://doi.org/10.1007/s11528-015-0842-1

[54] Jowallah, R. (2014). An investigation into the management of online teaching and learning spaces: A case study involving graduate research students. The International Review of Research in Open and Distributed Learning, 15(4). https://doi.org/10.19173/irrodl. v15i4.1585

[55] Huda, M., Yusuf, J. B., Azmi Jasmi, K., \& Zakaria, G. N. (2016). Understanding Comprehensive Learning Requirements in the Light of al-Zarnūjī's Ta 'lìm al-Muta 'allim. SAGE Open, 6(4), 2158244016670197. https://doi.org/10.1177/2158244016670197

[56] Jonassen, D. H., \& Grabowski, B. L. (2012). Handbook of individual differences, learning, and instruction. New York and London: Routledge

[57] Othman, R., Shahrill, M., Mundia, L., Tan, A., \& Huda, M. (2016). Investigating the Relationship Between the Student's Ability and Learning Preferences: Evidence from Year 7 Mathematics Students. The New Educational Review, 44(2), 125-138.

[58] Kreijns, K., Van Acker, F., Vermeulen, M., \& Van Buuren, H. (2013). What stimulates teachers to integrate ICT in their pedagogical practices? The use of digital learning materials in education. Computers in human behavior, 29(1), 217-225. https://doi.org/10.1016/ j.chb.2012.08.008

[59] Huda, M., Jasmi, K. A., Shahrill, M., Hehsan, A., Mustari, M. I., Basiron, B., \& Gassama, S. K. (2017). Empowering Children with Adaptive Technology Skills: Careful Engagement in the Digital Information Age. International Electronic Journal of Elementary Education, 9(3) (in press).

\section{$7 \quad$ Authors}

Miftachul Huda is with the Faculty of Islamic Civilisation, Universiti Teknologi Malaysia, Sekudai, 81310 Johor, Malaysia (halimelhuda@gmail.com)

Andino Maseleno is with the Centre for Lifelong Learning, Universiti Brunei Darussalam, BE 1410, Brunei Darussalam (andimaseleno@gmail.com).

Masitah Shahrill is with Sultan Hassanal Bolkiah Institute of Education, Universiti Brunei Darussalam, BE 1410, Brunei Darussalam (masitah.shahrill@ubd.edu.bn).

Kamarul Azmi Jasmi is with the Faculty of Islamic Civilisation, Universiti Teknologi Malaysia, Sekudai, 81310 Johor, Malaysia (qamar@utm.my).

Ismail Mustari is with the Faculty of Islamic Civilisation, Universiti Teknologi Malaysia, Sekudai, 81310 Johor, Malaysia (mohdismail@utm.my).

Bushrah Basiron is with the Faculty of Islamic Civilisation, Universiti Teknologi Malaysia, Sekudai, 81310 Johor, Malaysia (bushrah@utm.my).

Submitted 23 November 2016. Published as resubmitted by the authors 27 January 2017. 